\title{
Lymphocyte Sensitization in Asthma with Special Reference to Nature and Identity of Intrinsic Form
}

\author{
E. A. CASPARY, E. L. FEINMANN, E. J. FIELD
}

British Medical fournal, 1973, 1, 15-16

\section{Summary}

Studies of lymphocyte sensitization in patients with asthma showed that the intrinsic and extrinsic forms of the disease fell into two distinct groups. Intrinsic disease showed a general sensitization to a number of nonspecific antigens, while the extrinsic form had only slight elevation above normal values. These findings suggest that intrinsic asthma results from a defect of general immunity, whereas extrinsic asthma is a specific sensitization.

\section{Introduction}

Asthma has defied accurate description by many experts (Ciba Foundation Symposium, 1971) and many deny the existence of the intrinsic form, considering it to be a mixture of extrinsic disease responding to an as yet unidentified antigen and bronchitis with an element of spasm. Turner-Warwick and Haslam (1970), however, were able to show certain immunological differences between the intrinsic and extrinsic forms of asthma, having defined these two groups of patients in terms of their skin responses on prick testing to a standard range of common antigens and the presence or absence of supporting clinical history.

The extreme resistance of some cases of intrinsic asthma to treatment, including high doses of steroid, led us to attempt control of the process with immunosuppressive drugs and to monitor the efficacy of treatment with the sensitive macrophage electrophoretic mobility test (Field and Caspary, 1971). The immunological changes seen in these tests led to a comparative study of intrinsic and extrinsic asthma and form the basis of the present report.

\section{Patients and Methods}

A total of 28 patients were studied of whom 16 were thought to have intrinsic asthma. All of these 16 patients had variable bronchial obstruction and wheeze, required steroid in their treatment, and had shown an initial good response to treatment but had needed larger dosage for subsequent control. They had negative prick tests to all common antigens except candida and had had an eosinophilia of at least $500 / \mathrm{mm}^{3}$ before steroid. The age range of this group of patients was 35 to 64 (mean of 59) and the duration of disease varied from 3 to 24 years (mean of 11). All were on daily steroid $(5-30 \mathrm{mg})$ to control their symptoms. On the basis of additional tests four patients were thought to have coincident bronchitis or emphysema or both. The remaining 12 were selected as typical extrinsic asthma patients. They mainly showed positive skin tests to house pollens, and two patients were sensitive to Aspergillus fumigatus. All had eosinophilia greater than $500 / \mathrm{mm}^{3}$, had shown response to sodium cromoglycate (Intal), and also showed very variable bronchospasm as reflected by measurement of forced expiratory

Medical Research Council, Demyelinating Diseases Unit, Newcastle General Hospital, Newcastle upon Tyne NE4 6BE

E. A. CASPARY. M.SC., Member of Scientific Staff

E. J. FIELD, M.D., M.S., Honorary Director

Queen Elizabeth Hospital, Gateshead NE9 6SX

E. L. FEINMANN, M.R.C.P., Consultant Chest Physician

volume in one second. Their ages ranged from 13 to 55 years (mean of 35), three had had asthma since childhood, and the disease had been present for two to 20 years. Only one patient was thought to have coincident bronchitis.

Patients' lymphocytes were prepared from defibrinated blood as described by Hughes and Caspary (1970) by using methylcellulose and iron carbonyl. Guinea-pig macrophages were obtained after the injection of liquid paraffin and washing out the peritoneum after five to seven days with heparinized Hanks's solution. The washed peritoneal cells were irradiated with $100 \mathrm{r}$ of $\gamma$ radiation to inactivate (at least temporarily) the $10 \%$ of guinea-pig lymphocytes present in the exudate and prevent their participation in a mixed cell reaction.

The antigens used in the present study were encephalitogenic factor (Caspary and Field, 1965) (a histone-like basic protein made from human brain), a saline extract of human erector spinae muscle obtained at operation, egg albumen, BSA, Kveim reagent, and purified protein derivative.

Macrophage Electrophoretic Mobility Test.-In principle this method depends on the liberation of some factor(s) when sensitized lymphocytes react with specific antigen, this factor in turn reduces the electrophoretic mobility of normal macrophages in suspension and thus act as an indicator system for lymphocyteantigen interaction (Field and Caspary, 1971; Caspary, 1971, 1972). The procedure, described in detail by Caspary and Field (1971), was carried out as follows: $10^{7}$ normal guinea-pig peritoneal macrophages in $1.0 \mathrm{ml}$ of medium 199 were added to $0.5 \times 10^{6}$ of the human lymphocytes to be tested in $0.5 \mathrm{ml}$ of medium 199. A further $1.5 \mathrm{ml}$ of the same medium brought the total volume to $3.0 \mathrm{ml}$-a convenient one for the cytopherometer used. Migration time of the macrophages in this mixturethat is, without addition of antigen-was measured as "control" time. Antigen to be tested was added to the control mixture (33 $\mu \mathrm{g} / 1.0 \mathrm{ml}$ ) and the migration time of macrophages was estimated. This was done in a Zeiss cytopherometer under phase contrast so that macrophages could readily be distinguished by their size and content of liquid paraffin droplets. All specimens were scrambled and measured blind to eliminate observer bias. The time increase for migration over a fixed distance in the cytopherometer cell was expressed as a percentage of the "control time" - that is, when no antigen was present.

\section{Results}

The results of immunological studies on both extrinsic and intrinsic asthma patients and their comparison with similar tests on normal subjects are given in table I. These show a clear separation between their responses to a number of antigens and also suggest that perhaps some cases of extrinsic disease may have an element of the intrinsic form (cases 17, 19, 22, and 23). Statistical analysis shows that intrinsic asthma differs significantly from both normal control subjects and extrinsic asthma for all antigens tested, whereas extrinsic disease achieves significance only for encephalitogenic factor and BSA though showing values at the upper limit of normal for the other antigens when compared with normal subjects. In view of the possibility that these differences result from steroid treatment of the intrinsic group only, patients with other conditions on steroids were investigated and showed noticeable (immuno) suppression of cellular sensitization in contrast with intrinsic asthma (unpublished observations). A small proportion of both 
extrinsic and intrinsic cases tested with house dust, pollens, and Aspergillus fumigatus antigens (Bencard) showed appreciable sensitization in extrinsic asthma but gave values compatible

TABLE I-Lymphocyte Sensitization to Antigens in Patients Suffering from Intrinsic and Extrinsic Asthma and in Normal Control Subjects Expressed as Percentage Slowing in the Macrophage Electrophoretic Mobility Test

\begin{tabular}{|c|c|c|c|c|c|c|c|}
\hline $\begin{array}{l}\text { Case } \\
\text { No. }\end{array}$ & Sex and Age & $\begin{array}{c}\text { Encepha- } \\
\text { litogenic } \\
\text { Factor }\end{array}$ & $\underset{\text { Test }}{\text { Kveim }}$ & BSA & $\begin{array}{c}\text { Egg } \\
\text { Albumen }\end{array}$ & Muscle & $\begin{array}{c}\text { Purified } \\
\text { Protein } \\
\text { Derivative }\end{array}$ \\
\hline $\begin{array}{c}\text { Intrinsic: } \\
1 \\
2 \\
3 \\
4 \\
5 \\
6 \\
7 \\
8 \\
9 \\
10 \\
11 \\
12 \\
13 \\
14 \\
15\end{array}$ & $\begin{array}{ll}\text { F. } & 42 \\
\text { F. } & 59 \\
\text { F. } & 53 \\
\text { F. } & 43 \\
\text { M. } & 64 \\
\text { M. } & 46 \\
\text { F. } & 40 \\
\text { F. } & 39 \\
\text { F. } & 35 \\
\text { F. } & 54 \\
\text { F. } & 62 \\
\text { M. } & 60 \\
\text { F. } & 60 \\
\text { F. } & 46 \\
\text { F. } & 46\end{array}$ & $\begin{array}{r}14.6 \\
13.0 \\
14.5 \\
13.6 \\
11.3 \\
11.2 \\
11.2 \\
8.2 \\
11.6 \\
10.5 \\
9.8 \\
11.5 \\
12.8 \\
12.3 \\
11.0\end{array}$ & $\begin{array}{l}6 \cdot 9 \\
9 \cdot 7 \\
9 \cdot 3 \\
8 \cdot 6 \\
5 \cdot 6 \\
6 \cdot 2 \\
5 \cdot 5 \\
8 \cdot 6 \\
6 \cdot 3 \\
7 \cdot 1 \\
6 \cdot 8 \\
8 \cdot 0 \\
= \\
=\end{array}$ & $\begin{array}{l}6 \cdot 9 \\
9 \cdot 2 \\
8 \cdot 4 \\
7 \cdot 5 \\
4 \cdot 8 \\
6 \cdot 1 \\
5 \cdot 7 \\
2 \cdot 9 \\
6 \cdot 7 \\
7 \cdot 5 \\
6 \cdot 5 \\
6 \cdot 1 \\
4 \cdot 4 \\
4 \cdot 7 \\
4.9\end{array}$ & $\begin{array}{l}7 \cdot 9 \\
8 \cdot 6 \\
7 \cdot 0 \\
4 \cdot 2 \\
5 \cdot 9 \\
5 \cdot 2 \\
2 \cdot 9 \\
6 \cdot 6 \\
9 \cdot 2 \\
7 \cdot 5 \\
2 \cdot 7 \\
4 \cdot 5 \\
4 \cdot 5 \\
5 \cdot 2\end{array}$ & $\begin{array}{l}\bar{Z} \\
8 \cdot 3 \\
\bar{Z} \\
6 \cdot 2 \\
6 \cdot 3 \\
5 \cdot 5 \\
7 \cdot 1 \\
8 \cdot 2 \\
8 \cdot 0 \\
9 \cdot 4 \\
5 \cdot 5 \\
5 \cdot 1 \\
5.9\end{array}$ & $\begin{array}{l}15 \cdot 4 \\
16 \cdot 7 \\
17 \cdot 7 \\
14 \cdot 6 \\
15 \cdot 1 \\
15 \cdot 8 \\
15 \cdot 1 \\
13 \cdot 4 \\
17 \cdot 1 \\
17 \cdot 1 \\
16 \cdot 0 \\
18 \cdot 0 \\
= \\
=\end{array}$ \\
\hline $\begin{array}{c}\text { Extrinsic: } \\
16 \\
17 \\
18 \\
19 \\
20 \\
21 \\
22 \\
23 \\
24 \\
25 \\
26\end{array}$ & $\begin{array}{ll}\text { F. } & 22 \\
\text { F. } & 35 \\
\text { M. } & 47 \\
\text { M. } & 34 \\
\text { M. } & 44 \\
\text { F. } & 43 \\
\text { F. } & 24 \\
\text { M. } & 13 \\
\text { M. } & 34 \\
\text { F. } & 42 \\
\text { M. } & 55\end{array}$ & $\begin{array}{l}2.9 \\
9.1 \\
3.4 \\
5.1 \\
1.9 \\
4.4 \\
6.2 \\
5.3 \\
2.3 \\
1.7 \\
1.3\end{array}$ & $\begin{array}{l}1 \cdot 8 \\
6 \cdot 3 \\
1 \cdot 9 \\
2 \cdot 9 \\
2 \cdot 2 \\
0 \cdot 1 \\
2 \cdot 7 \\
3 \cdot 6 \\
2 \cdot 3 \\
0 \cdot 6 \\
1 \cdot 4\end{array}$ & $\begin{array}{l}\overline{6.5} \\
2.3 \\
2.8 \\
2.3 \\
1.8 \\
3.4 \\
1.8 \\
1.2 \\
1.7 \\
1.5\end{array}$ & $\begin{array}{l}2.3 \\
5.9 \\
1.9 \\
2.8 \\
0.9 \\
1.0 \\
1.4 \\
3.1 \\
1.5 \\
2 \cdot 2 \\
0.8\end{array}$ & $\begin{array}{l}1.4 \\
6.3 \\
2.0 \\
2.9 \\
1.9 \\
1.3 \\
2.5 \\
1.9 \\
3.0 \\
1.9 \\
0.2\end{array}$ & $\begin{array}{l}17 \cdot 9 \\
16 \cdot 0 \\
16 \cdot 5 \\
15 \cdot 9 \\
16 \cdot 1 \\
18 \cdot 4 \\
16 \cdot 0 \\
17 \cdot 6 \\
16 \cdot 9 \\
16 \cdot 4 \\
17 \cdot 4\end{array}$ \\
\hline $\begin{array}{l}\text { Normal } \\
\text { Subjects } \\
\text { (mean) }\end{array}$ & & $\begin{array}{c}1.4 \\
(45)\end{array}$ & $\begin{array}{l}1.5 \\
(15)\end{array}$ & $\begin{array}{l}1 \cdot 1 \\
(70)\end{array}$ & $\begin{array}{l}1 \cdot 1 \\
(27)\end{array}$ & $\begin{array}{l}1.5 \\
(28)\end{array}$ & $15-20$ \\
\hline
\end{tabular}

TABLE II-Lymphocyte Sensitization to House Dust, Pollen, and Aspergillus Skin Test Antigens in Intrinsic and Extrinsic Asthma Expressed as Percentage Slowing in the Test

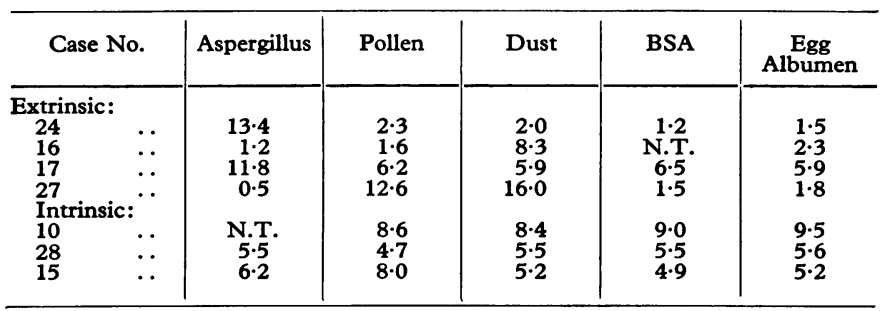

N.T. $=$ Not tested. with those obtained for non-specific antigens-for example, egg, BSA, etc.-in intrinsic disease (table 2). Some of the skin test antigens, however, showed inherent toxicity in our test system and would require further purification to confirm these results.

\section{Discussion}

The general picture of immune sensitization in asthma shows a clear division into two groups corresponding to a clinical classification of extrinsic and intrinsic disease, including a few extrinsic cases showing some element of intrinsic disease. The classical extrinsic asthma cases showed pronounced lymphocyte sensitization to the antigen inducing their disease, but little sensitization to a battery of other antigens. On the other hand, intrinsic asthma showed noticeable sensitization to the same battery of antigens without specificity to any particular one. These findings suggest that intrinsic disease is a disorder of general immunity, while the extrinsic form appears as a predominantly specific sensitization. The immunological evidence of Hall et al. (1966) and Turner-Warwick and Haslam (1970) also points in the same direction.

Clinical evidence in intrinsic asthma also suggests a defect of general immunity. In two patients the onset of asthma coincided with the onset of rheumatoid disease, and a further two patients developed severe polyarthritis, in one accompanied by erythema nodosum, after a change in therapy from oral steroid to topical beclomethasone. The changes after alteration in therapy could, alternatively, have resulted from the withdrawal of systemic steroid as described by others.

\section{References}

Caspary, E. A. (1971). Nature Nerw Biology, 231, 24.

Caspary, E. A. (1972). Clinical and Experimental Immunology, 11, 305. Caspary, E. A., and Field, E. J. (1965). Proceedings of the New York Academy of Sciences, 122, 182.

Caspary, E. A., and Field, E. J. (1971). British Medical fournal, 2, 613.

CIBA Foundation Symposium (1971). Identification of Asthma, No. 38. London, Churchill.

Field, E. J., and Caspary, E. A. (1971). Fournal of Clinical Pathology, 24, 179. Hall, R., Turner-Warwick, M., and Doniach, D. (1966). Clinical and Experimental Immunology 1, 285.

Hughes, D., and Caspary, E. A. (1970). International Archives of Allergy, 37, 506.

Turner-Warwick, M., and Haslam, P. (1970). Clinical and Experimental Immunology, 7, 31 .

\title{
Immunological Studies in Ugandan Patients with Hepatocellular Carcinoma
}

\author{
ARON PRIMACK，CHARLES L. VOGEL， LEWELLYS F. BARKER
}

British Medical fournal, 1973, 1, 16-19

\section{Summary}

Immunological studies were performed on Ugandan patients with hepatocellular carcinoma to test the hypothesis that the high rate of persistence of hepatitisassociated antigen in these patients is the result of defects in host immune response. The responses to 1-chloro-

Uganda Cancer Institute, Kampala, Uganda

CHARLES L. VOGEL, M.D., Director, Solid Tumour Centre

Bureau of Biologics, Food and Drug Administration, Rockville, Maryland, U.S.A.

LEWELLYS F. BARKER, M.D., Division of Virology 2,4-dinitrobenzene sensitization and to a battery of recall skin test antigens were normal, as was the humoral antibody response to tularaemia antigen. Neither hypogammaglobulinaemia nor specific immunoglobulin deficiencies were found. Thus it appears unlikely that generalized defects in host immune responses can account for the high incidence of persistent hepatitis $B$ virus infection found in Ugandan patients with hepatocellular carcinoma.

\section{Introduction}

Hepatitis-associated antigen (H.A.A., hepatitis B antigen, Australia antigen) is found persistently in the blood of $40 \%$ of 